Article

\title{
Reduced-Pressure Process for Fabricating Tea Tree Oil-Polyvinylpyrrolidone Electrospun Fibers
}

\author{
Li Zhu ${ }^{1} \mathbb{D}$, Siti Machmudah ${ }^{2}$, Wahyudiono ${ }^{1}\left(\mathbb{D}\right.$, Hideki Kanda ${ }^{1, *(\mathbb{D})}$ and Motonobu Goto ${ }^{1, * \mathbb{D}}$ \\ 1 Department of Materials Process Engineering, Nagoya University, Furo-cho, Chikusa-ku, \\ Nagoya 464-8603, Japan; zhu.li@g.mbox.nagoya-u.ac.jp (L.Z.); wahyudiono@b.mbox.nagoya-u.ac.jp (W.) \\ 2 Department of Chemical Engineering, Institut Teknologi Sepuluh Nopember, Surabaya 60111, Indonesia; \\ machmudah@chem-eng.its.ac.id \\ * Correspondence: kanda.hideki@material.nagoya-u.ac.jp (H.K.); goto.motonobu@material.nagoya-u.ac.jp (M.G.)
}

Citation: Zhu, L.; Machmudah, S.; Wahyudiono; Kanda, H.; Goto, M.

Reduced-Pressure Process for

Fabricating Tea Tree

Oil-Polyvinylpyrrolidone

Electrospun Fibers. Polymers 2022, 14

743. https://doi.org/10.3390/

polym14040743

Academic Editor: Deng-Guang Yu

Received: 15 January 2022

Accepted: 9 February 2022

Published: 15 February 2022

Publisher's Note: MDPI stays neutral with regard to jurisdictional claims in published maps and institutional affiliations.

Copyright: (C) 2022 by the authors. Licensee MDPI, Basel, Switzerland. This article is an open access article distributed under the terms and conditions of the Creative Commons Attribution (CC BY) license (https:// creativecommons.org/licenses/by/ $4.0 /)$.

\begin{abstract}
Electrospun fibers containing tea tree oil (TTO) can be explored for practical applications due to the antimicrobial and anti-inflammatory activities of TTO. Considering that there are potentially toxic components in TTO, it is necessary to eliminate or reduce its content in the preparation process of TTO-doped electrospun fibers. In this work, electrospun TTO-PVP (polyvinylpyrrolidone) fibers containing an $18.18 \mathrm{wt}$.\% decreased content of 1,8-Cineole were successfully fabricated by intense evaporation of a self-made reduced-pressure electrospinning (RP-ES) setup (as low as $94.4 \mathrm{kPa}$ ). In addition, such intense evaporation led to a morphology change, where a typical average fiber diameter increased from 0.831 to $1.148 \mu \mathrm{m}$, fewer and smaller beads in fibers, along with a rougher and grooves fiber surface. These morphology changes allowed Terpinen-4-ol to remain in the fiber for a more extended period. In addition, RP-ES proved the possibility for intense evaporation and continuous vapor removal by continuously environmental vacuum pumping of electrospinning.
\end{abstract}

Keywords: electrospinning; reduced pressure; evaporation; tea tree oil

\section{Introduction}

Tea tree oil (TTO) is a volatile essential oil extracted from Australian Melaleuca alternifolia by steam distillation and is valued globally for its antimicrobial and anti-inflammatory activities [1,2]. There have been works of literature focusing on the prominent effects of TTO and the synthesis of TTO-doped composites. For example, Ge et al. [3] reported dispersed and immersed TTO emulsion droplets in chitosan films for wound healing applications. Silva et al. [4] prepared tea tree oil-loaded core-shell nanocapsules for acne treatment. El-Wakil et al. [5] reported antimicrobial bio-composites based on rice bran with TTO with excellent possibility of food packaging and biomedical purposes.

Here, Terpinen-4-ol is the primary functional component of TTO and shows promising antibacterial [6-8], anti-inflammatory [9], anti-mite [10], and anti-lice [11] properties. However, 1,8-Cineole, another component of TTO, is responsible for potential skin irritation [12] and potential toxicity of kidneys [13] and fetal [14]. The TTO standard proposed by the International Organization for Standardization (ISO) proposed stipulates a limit for the 1,8 -Cineole concentration in products, and selective removal of 1,8-Cineole from TTO is necessary for safe and comfortable use of TTO [15].

A possible solution to the selective removal of 1,8-cineole from TTO is based on the volatility differences. It has been reported that the boiling point of 1,8 -Cineole $\left(176-177^{\circ} \mathrm{C}\right)$ is lower than Terpinen-4-ol $\left(212{ }^{\circ} \mathrm{C}\right)$. In addition, 1,8-Cineole shall have a higher vapor pressure $\left(1.90 \mathrm{mmHg}\right.$ at $\left.25^{\circ} \mathrm{C}\right)$ than Terpinen-4-ol $\left(0.048 \mathrm{mmHg}\right.$ at $\left.25^{\circ} \mathrm{C}\right)$ [16-19]. This assumption has been experimentally proved by literature work as well. It has been reported by Leach et al. [20], that 1,8-Cineole has higher volatility, and with compared, Terpinen-4-ol has relatively low volatility. In this case, it is possible to control and adjust the content 
of 1,8-Cineole and Terpinen-4-ol in TTO-doped materials if the environmental pressure during material synthesis shall be reduced.

This work was to fabricate microscale TTO-doped fibers using electrospinning technology, which is widely studied and future industrialized with various applications such as drug delivery, medicine, sensors, and cosmetics. Here, fast evaporation is essential for the electrospinning process [21-23]. This paper proposed a self-design reduced-pressure electrospinning (RP-ES) setup was to enhance the evaporation and continuous vapor removal ability of the polymer-solvent and volatile components. The reduced pressure is based on a vacuum pump that continuously vacuums the chamber with a considerable size $\left(0.15 \mathrm{~m}^{3}\right)$ where RP-ES is located. Through our tests, this setup successfully fabricated different electrospun fiber mats. Upon a reduced pressure, more 1,8-Cineole volatilized of jetting micron-sized droplets, resulting in a high content of the Terpinene-4-ol solution, which could improve the application quality of TTO-doped electrospun fibers.

For practical TTO-doped fiber composites, there are different polymer hosts such as TTO-polylactic acid (PLA) [24], TTO-polyethylene oxide (PEO) [25,26], and TTO-polyurethane (PU) [27]. This study selected polyvinylpyrrolidone (PVP) as the polymer host to fabricate TTO-PVP electrospun fibers. PVP has a wide range of safe applications among various polymers in medicine, pharmacy, cosmetics, and industrial fabrication because it is nontoxic, physiologically compatible, temperature resistant, $\mathrm{pH}$ stable, chemically inert [28].

\section{Materials and Methods}

\subsection{Materials}

Tea tree oil (TTO) was obtained from Guangdong Academy of Forestry (Guangzhou, China), and GC-MS analyzed it according to Tranchida et al. [19]. The TTO comprised 38.68\% Terpinen-4-ol and 4.29\% 1,8-Cineole, which was complied with ISO 4730:2017. Polyvinylpyrrolidone (PVP average MW 1,300,000) was purchased from Sigma-Aldrich (St. Louis, MO, USA). Ethanol (99.5\%) was purchased from Wako Pure Chemical Industries (Osaka, Japan).

For the quantitative analysis of TTO components, the 1,8-Cineole standard (99\%, CAS: 470-82-6, Catalog Number: C80601) was purchased from Sigma-Aldrich (St. Louis, MO, USA). The Terpinen-4-ol standard (CAS: 562-74-3, Catalog Number: T117500) was purchased from Toronto Research Chemicals (Toronto, ON, Canada).

\subsection{Methods}

\subsubsection{Experimental Setup}

As described in Figure 1, a typical electrospinning system was placed in a $0.15 \mathrm{~m}^{3}$ acrylic chamber connected to a rotary vane vacuum pump (GHD-030, ULVAC, Inc., Miyazaki, Japan ) and a ball valve controlling the pressure from atmospheric (ATM) pressure $(101.3 \mathrm{kPa})$ to reduced-pressure $(\mathrm{RP}) 94.4 \mathrm{kPa}$. The flow rate was set as $0.4 \mathrm{~L} / \mathrm{min}$, and fresh air from the airflow meter was set to remove solvent vapor. A high-pressure syringe pump (PHD-Ultra 4400, Harvard Apparatus, Holliston, USA) was injected into a $0.25 \mathrm{~mm}$ needle at a $0.1 \mathrm{~mL} / \mathrm{min}$ flow rate. A DC voltage of $12 \mathrm{kV}$ power supply (HARb-30P1, Matsusada Precision, Osaka, Japan) applied an electric field to the TTO-PVP polymer solution to produce a jet that accelerated from the needle to the collector at a distance of $12 \mathrm{~cm}$ [29]. The above experiments were carried out at $22-24{ }^{\circ} \mathrm{C}$ and $21-28 \%$ relative humidity using a digital thermo-hydro indicator (THI-HP, AS ONE Corporation, Osaka, Japan).

\subsubsection{GC-MS Analysis}

The phytochemical parameters of the TTO, pure PVP and TTO-PVP electrospun fibers were identified by Gas Chromatography-Mass Spectrometry (GC-MS; Agilent 7890A GC and Agilent 5975C MS; Agilent Technologies, Inc., Santa Clara, CA, USA) and an HP-5ms capillary column ( $30 \mathrm{~mm}, 0.25 \mathrm{~mm}$ i.d., $0.25 \mu \mathrm{m}$ film thickness; Agilent Technologies, Inc., Santa Clara, CA, USA). The chromatograph was programmed from 50 to $280^{\circ} \mathrm{C}$ at a rate of $3{ }^{\circ} \mathrm{C} / \mathrm{min}$. Helium was used as the carrier at a $24 \mathrm{~mL} / \mathrm{min}$ flow rate. 


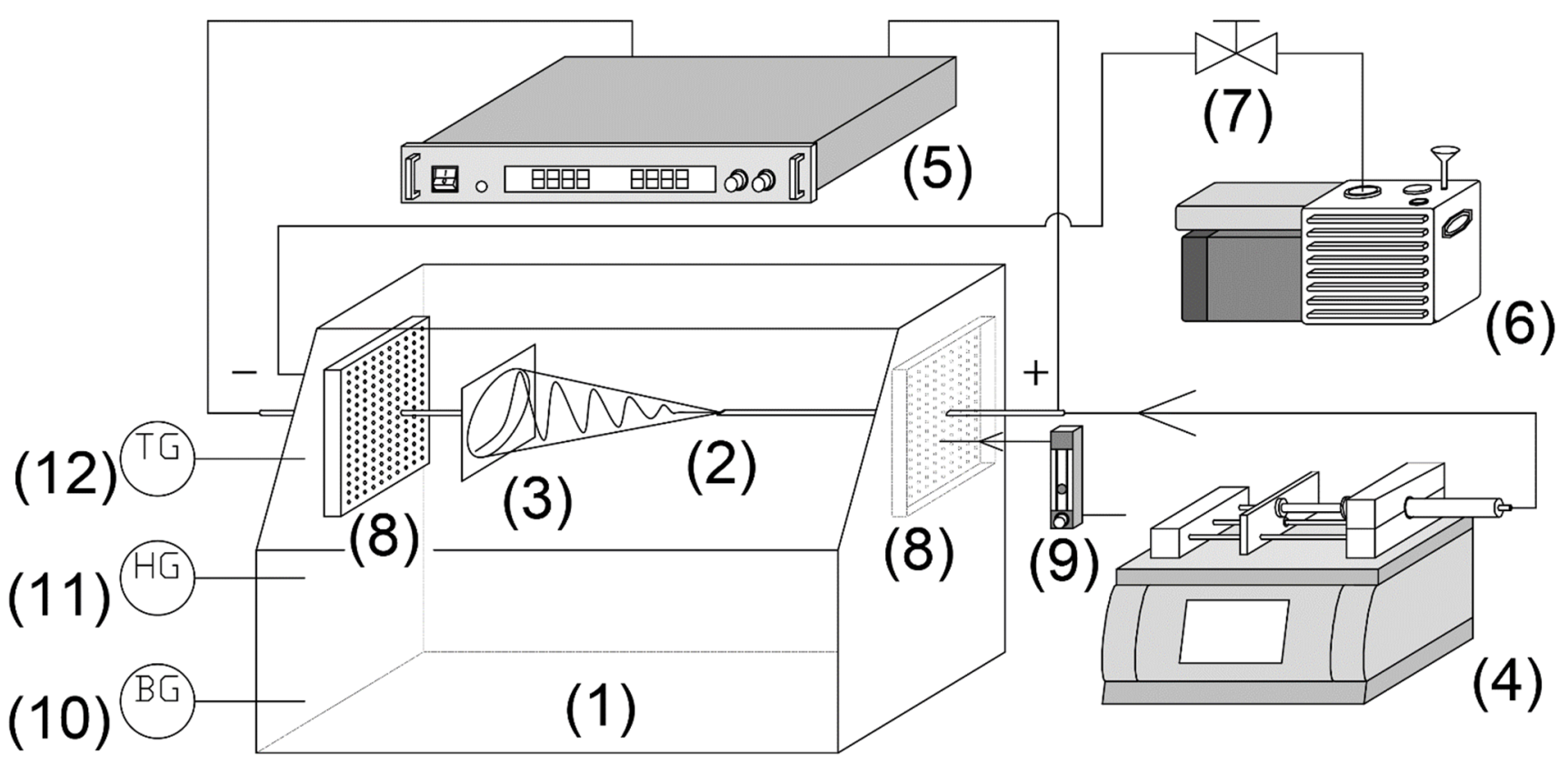

Figure 1. Experimental setup for electrospinning; (1) $0.15 \mathrm{~m}^{3}$ acrylic chamber, (2) nozzle, (3) fiber collector, (4) high-pressure syringe pump, (5) high-voltage power supply, (6) vacuum pump, (7) pressure control ball-valve, (8) baffle plate, (9) airflow meter, (10) barometer gauge, (11) humidity gauge, (12) temperature gauge.

As shown in Figure 2, the absolute calibration curves between peak area and concentration of 1,8-Cineole and Terpinen-4-ol were plotted, and the four-point quantitative linear correlation coefficients (R2) were 0.9959 and 0.9975 , respectively.

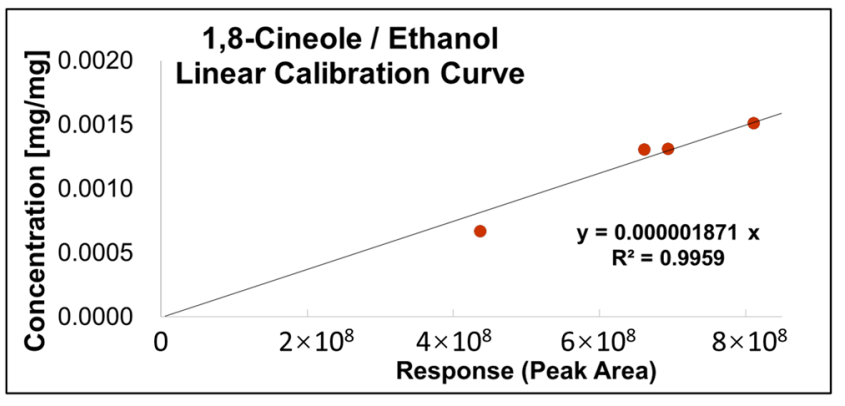

(a)

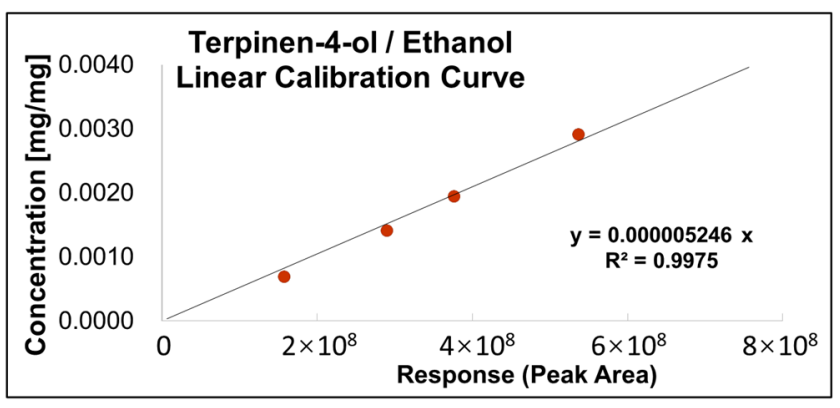

(b)

Figure 2. Linear calibration curve of the relationship between peak area and concentration with (a) 1,8-Cineole, and (b) Terpinen-4-ol by GC-MS.

\subsubsection{Antibacterial Test}

The density of Staphylococcus aureus $\left(\mathrm{NBRC}^{\circledR} 12732^{\mathrm{TM}}\right)$ strains suspension was grown in the Trypticase Soy Broth and adjusted by using a UV-vis spectrophotometer (V-550, JASCO, Tokyo, Japan) for $0.5 \mathrm{McF}$ arland Standard with 0.1 reading absorbance at $600-\mathrm{nm}$ [30]. The 10-day room condition exposed electrospun nanofiber discs (20 mg) were placed on Muller Hinton Agar and incubated at $37^{\circ} \mathrm{C}$ medium for $48 \mathrm{~h}$.

\subsubsection{Other Characterizations}

The TTO, pure PVP, and TTO-PVP electrospun fibers were characterized using scanning electron microscope (SEM; S-4300, Hitachi, Tokyo, Japan) with a gold sputtering coating (RMC-Eiko RE vacuum coater, Eiki Engineering Co., Ltd., Ibaraki, Japan), thermogravimetricdifferential thermal analysis (TG-DTA; TGA-50, Shimadzu, Kyoto, Japan), differential 
scanning calorimetry (DSC; DSC-60A, Shimadzu, Kyoto, Japan), and Fourier transform infrared spectroscopy at $4 \mathrm{~cm}^{-1}$ resolution (FT-IR; PerkinElmer Ltd., Waltham, MA, USA).

\section{Results and Discussion}

3.1. Fibers Morphologies

\subsubsection{The Ratio of TTO to PVP}

PVP was first dissolved in ethanol for the polymer solution at a concentration of 10 wt.\% based on previous research [31,32]. As shown in Figure 3, TTO-PVP electrospun fiber mats were prepared under an atmospheric environment. When the TTO concentration (of polymer solution) was higher than $15 \mathrm{wt}$ \%, the electrospun fiber mat was deformed and became a transparent slimy film. The TTO of $10 \mathrm{wt}$ \% or less could obtain electrospun fiber. Therefore, $10 \%$ by weight has a relatively high TTO percentage for the functional TTO-PVP electrospun fiber mats. The weight percentage of TTO:PVP = 1:1 electrospun fibers was to study for the following research.
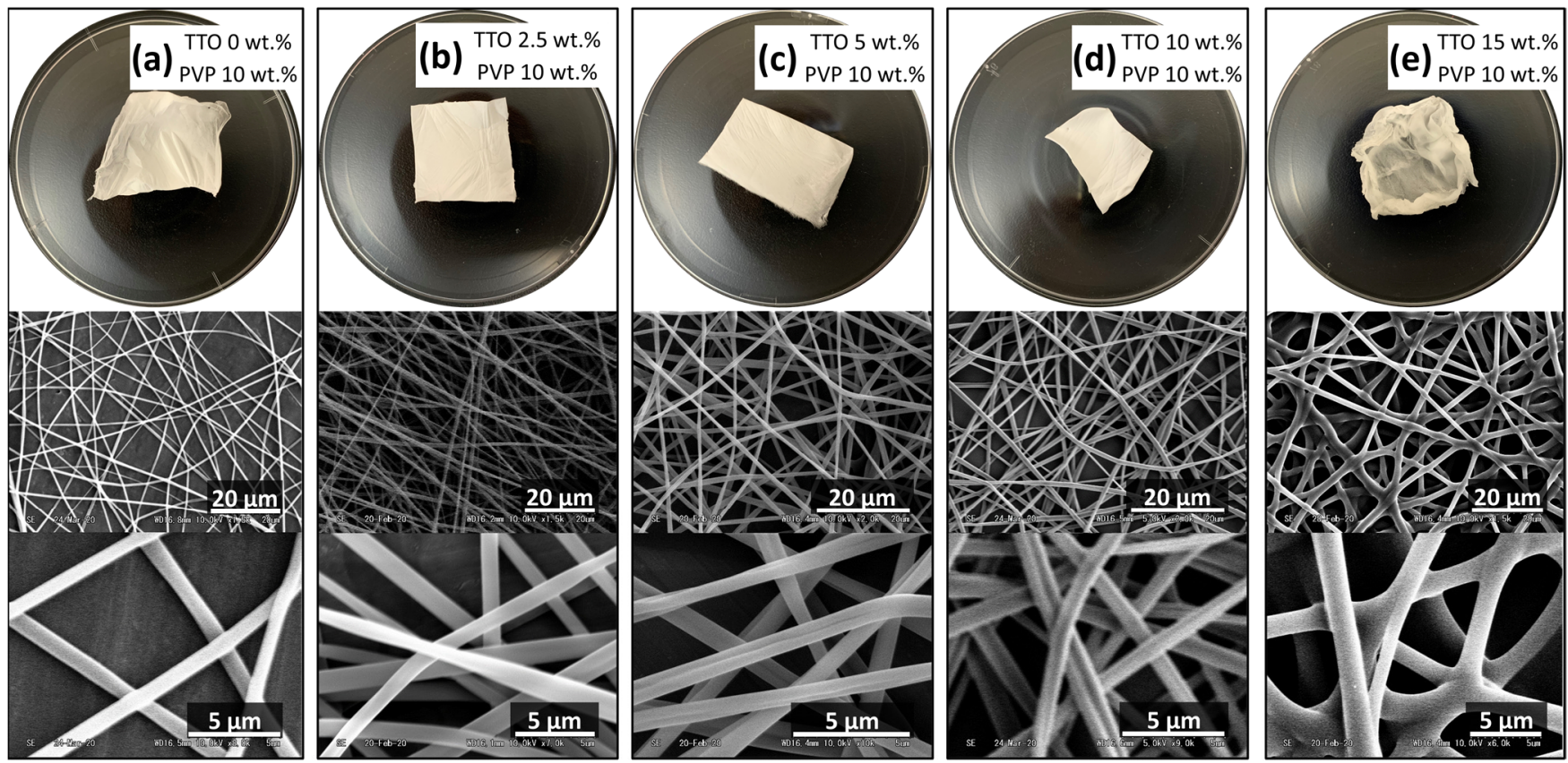

Figure 3. Appearances and SEM images of $10 \mathrm{wt}$.\% PVP fiber mat by typical atmospheric electrospinning with (a) 0 wt.\%, (b) 2.5 wt.\%, (c) 5 wt.\%, (d) 10 wt.\%, and (e) 15 wt.\% TTO.

\subsubsection{Fibers Formation by RP-ES}

Figures 4 and 5 showed that pure PVP and TTO-PVP electrospun fiber mats could be fabricated with 7-10 wt.\% pure PVP and 7-10 wt.\% TTO-PVP ethanol-based polymer solution at the environmental pressures from atmospheric $101.3 \mathrm{kPa}$ to reduced-pressure $94.4 \mathrm{kPa}$. It is viewed from SEM images that the individual electrospun fibers were randomly distributed on the supporting base, with no branch structure or large knots. It also supported the feasibility of operating reduced pressure electrospinning to obtain the micro-scale fibers. 


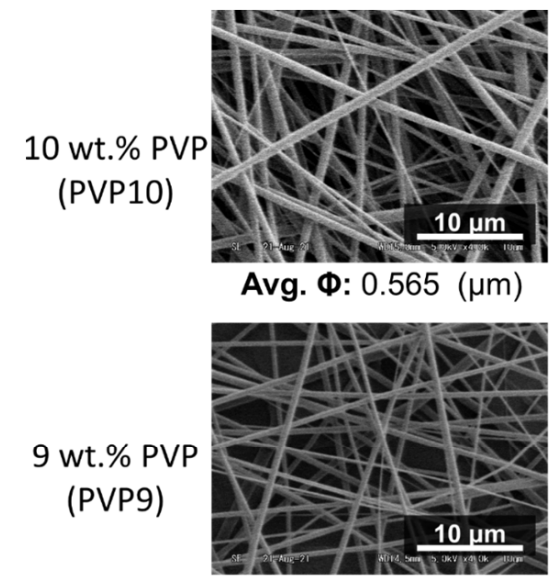

Avg. Ф: $0.465(\mu \mathrm{m})$

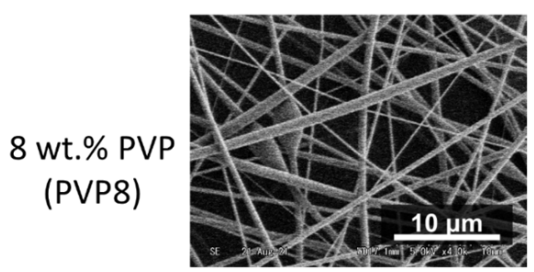

Avg. $\Phi: 0.357(\mu \mathrm{m})$

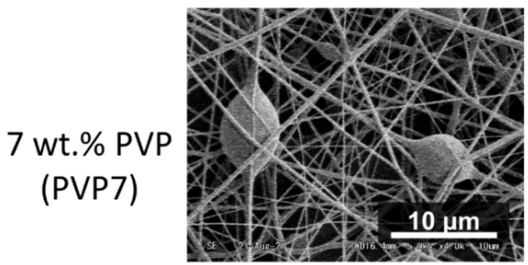

Avg. Ф: $0.339(\mu \mathrm{m})$

Atmospheric

$101.3 \mathrm{kPa}$

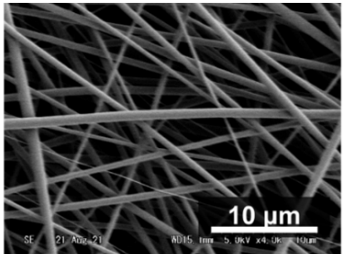

Avg. Ф: $0.661(\mu \mathrm{m})$

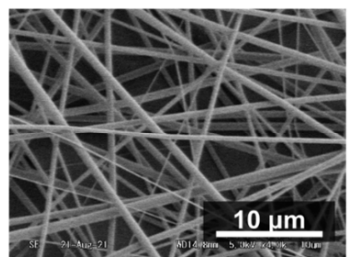

Avg. Ф: $0.559(\mu \mathrm{m})$

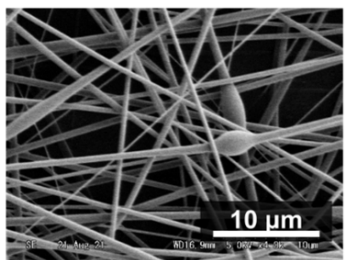

Avg. Ф: $0.397(\mu \mathrm{m})$

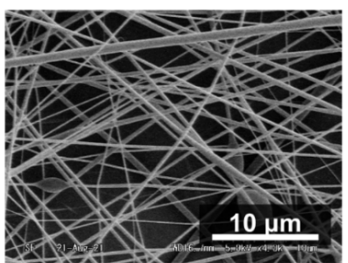

Avg. Ф: $0.373(\mu \mathrm{m})$

Reduced Pressure

$98.9 \mathrm{kPa}$

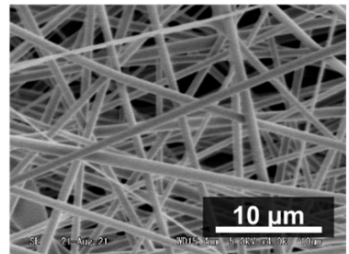

Avg. Ф: $0.761(\mu \mathrm{m})$

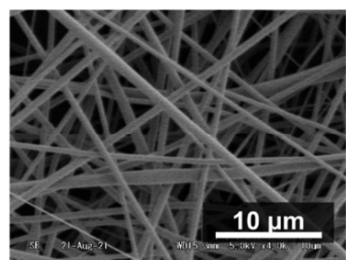

Avg. Ф: $0.668(\mu \mathrm{m})$

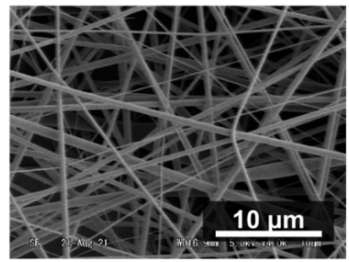

Avg. Ф: $0.409(\mu \mathrm{m})$

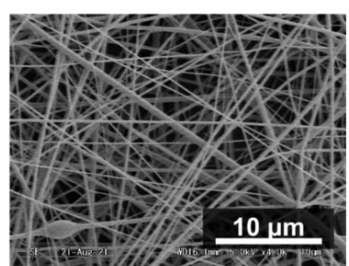

Avg. Ф: $0.389(\mu \mathrm{m})$

Reduced Pressure

$96.6 \mathrm{kPa}$

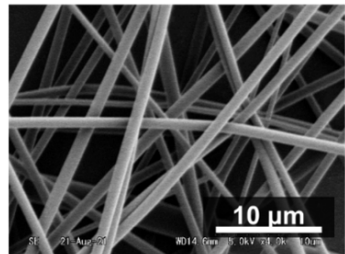

Avg. $\Phi: 0.814(\mu \mathrm{m})$

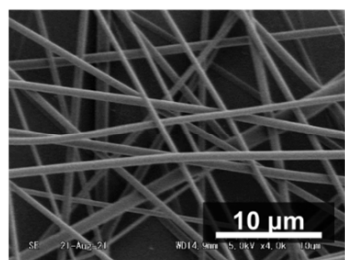

Avg. Ф: $0.694(\mu \mathrm{m})$

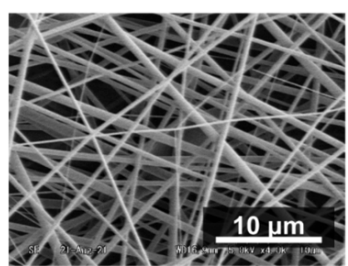

Avg. $\Phi: 0.421$ ( $\mu \mathrm{m})$

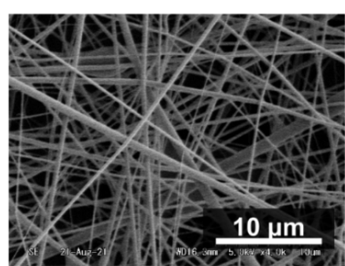

Avg. Ф: $0.398(\mu \mathrm{m})$

Reduced Pressure

$94.4 \mathrm{kPa}$

Figure 4. SEM images and average fiber diameter of pure PVP electrospun fibers.

\subsubsection{Fibers Diameter by RP-ES}

The averaged fiber diameter was measured by SEM image using ImageJ $1.51 \mathrm{w}$ at 150 randomly selected fibers. As shown in Figure 6, the average diameters of 7, 8, 9, 10 wt.\% TTO and PVP electrospun fibers were increased as the pressure decreased with intense vacuum pumping. For example, the diameter of $10 \mathrm{wt}$ \% TTO-PVP electrospun fiber increased from $0.831 \mu \mathrm{m}$ of atmospheric $101.3 \mathrm{kPa}$ to $1.148 \mu \mathrm{m}$ of reduced pressure $94.4 \mathrm{kPa}$. This result could also indicate that if an electrospun fiber mat product with a smaller diameter is required, the wt.\% of PVP in the polymer solution in RP-ES could be appropriately reduced.

\subsubsection{Less Bead-Fibers by RP-ES}

For 8 wt.\% pure PVP and 8 wt.\% TTO-PVP electrospun fibers, it has been observed that the typical atmospheric electrospun of Figure 7a,e usually have the largest size and more micron-sized beads. The size and number of beads decrease with the enhanced vacuum pumping of Figure $7 \mathrm{~b}-\mathrm{d}, \mathrm{f}-\mathrm{h}$. Bead-fibers are related to the concentration of PVP. When the PVP concentration is low, micron beads appear because of their low viscosity and cannot overcome the surface tension of the solution [33]. Increasing the concentration of PVP can avoid the appearance of bead-fibers. It also shows that RP-ES increases the viscosity of the polymer solution through the evaporation of the solvent. 


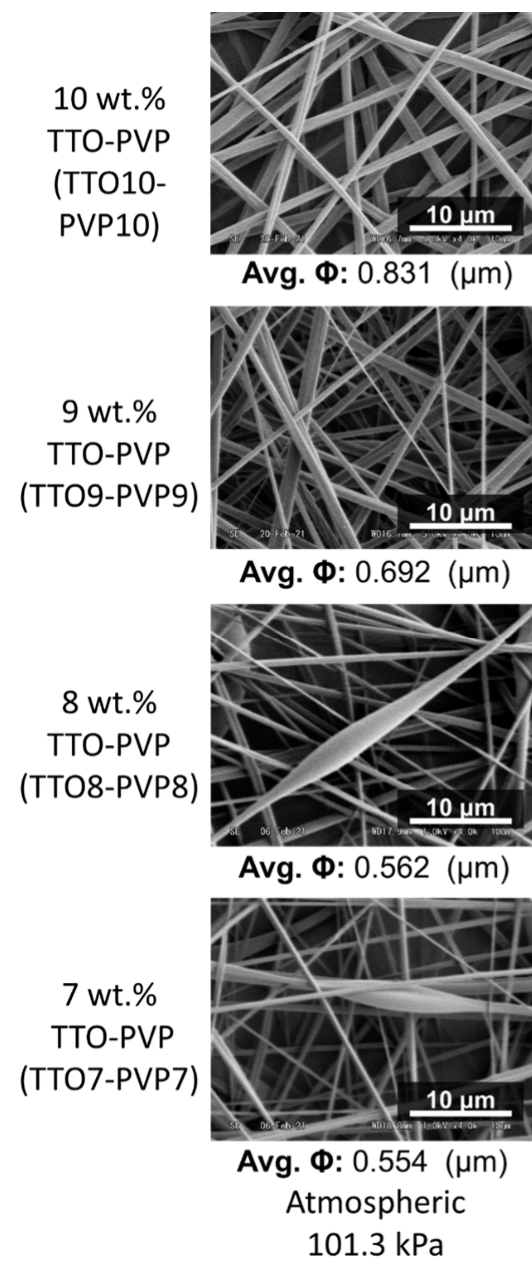

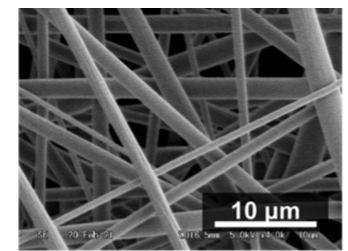

Avg. $\Phi: 1.037(\mu \mathrm{m})$

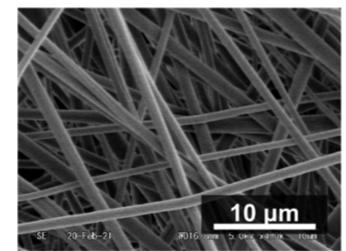

Avg. Ф: $0.908(\mu \mathrm{m})$
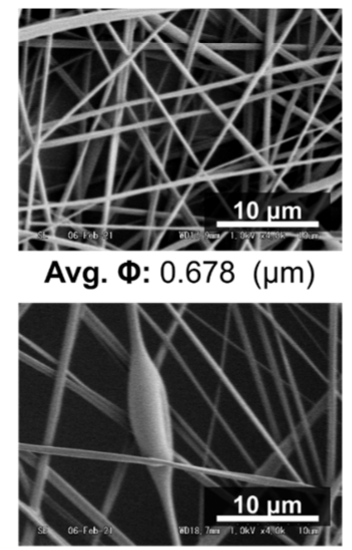

Avg. $\Phi: 0.669(\mu \mathrm{m})$ Reduced Pressure $98.9 \mathrm{kPa}$

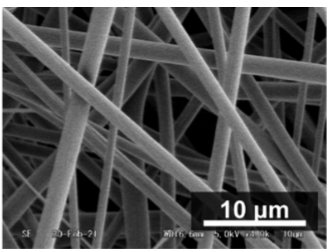

Avg. Ф: $1.124(\mu \mathrm{m})$

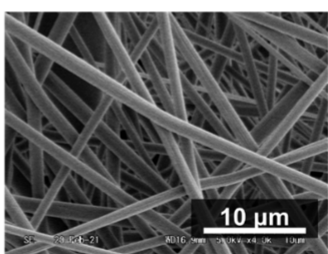

Avg. $\Phi: 1.012(\mu \mathrm{m})$

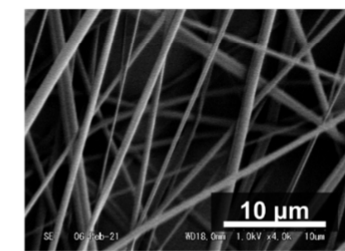

Avg. Ф: $0.725(\mu \mathrm{m})$

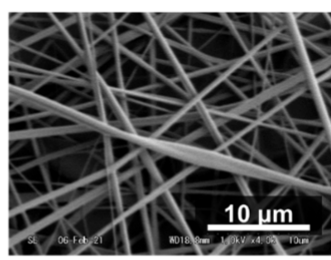

Avg. Ф: $0.717(\mu \mathrm{m})$ Reduced Pressure $96.6 \mathrm{kPa}$

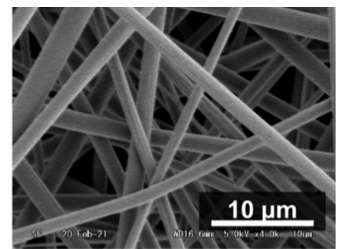

Avg. Ф: $1.148(\mu \mathrm{m})$

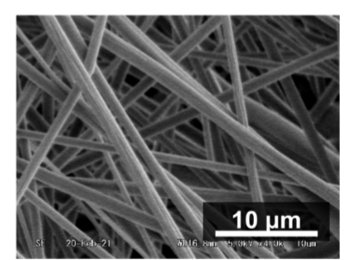

Avg. $\Phi: 1.075(\mu \mathrm{m})$

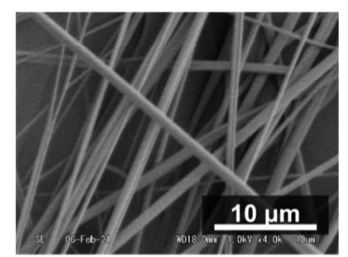

Avg. $\Phi: 0.766(\mu \mathrm{m})$

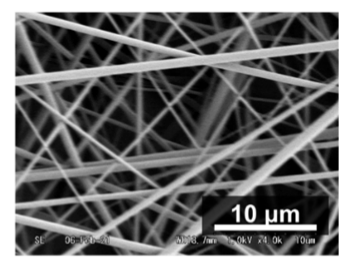

Avg. Ф: $0.741(\mu \mathrm{m})$

Reduced Pressure

$94.4 \mathrm{kPa}$

Figure 5. SEM images and average fiber diameter of TTO-PVP electrospun fibers.

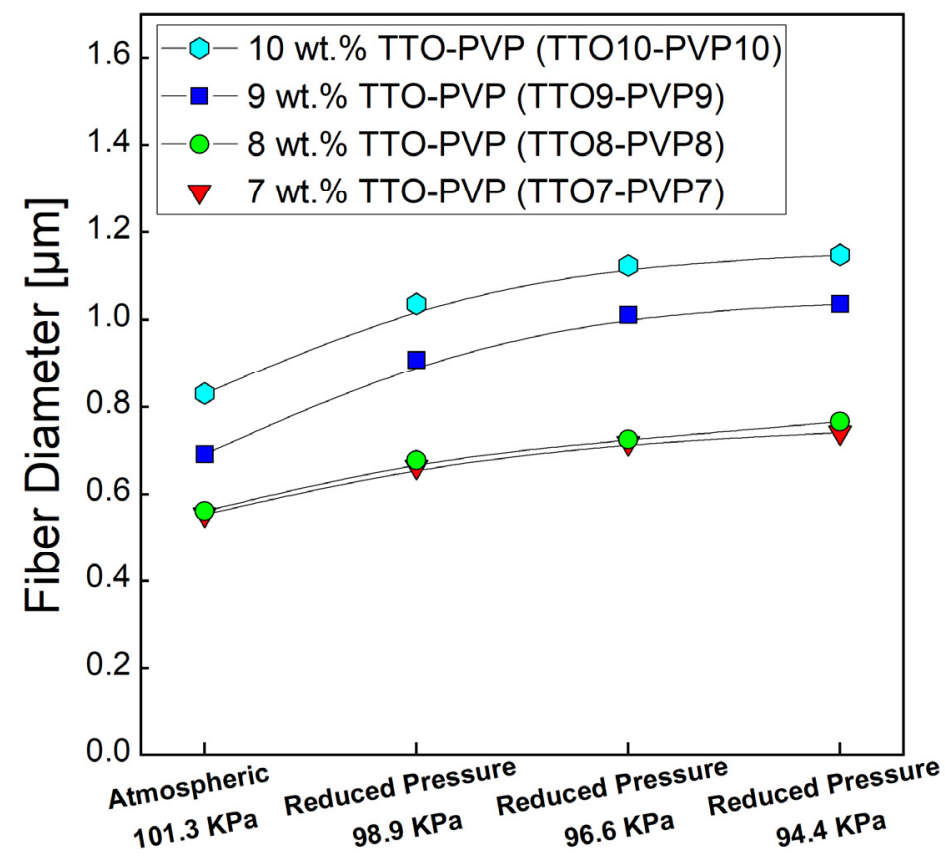

Environmental Pressure

Figure 6. Distribution of TTO-PVP electrospun fibers diameter. 


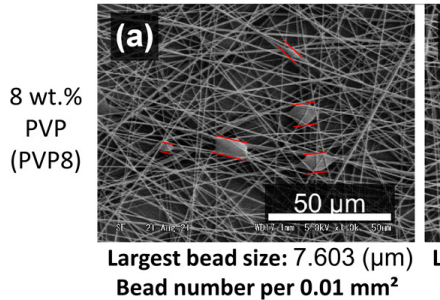

( $\sim 50$ fibers): 5

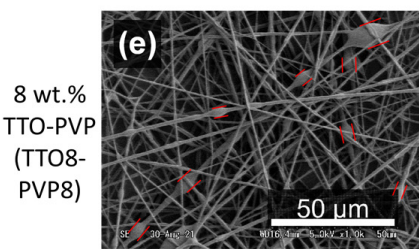

Largest bead size: $8.205(\mu \mathrm{m})$ Bead number per $0.01 \mathrm{~mm}^{2}$

( $\sim 50$ fibers): 8

Atmospheric

$101.3 \mathrm{KPa}$

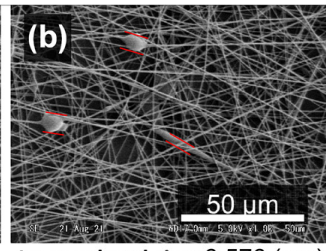

Largest bead size: $6.576(\mu \mathrm{m})$ Bead number per $0.01 \mathrm{~mm}^{2}$ ( $\sim 50$ fibers): 3

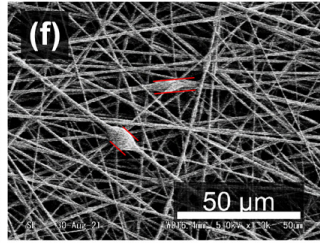

Largest bead size: $6.089(\mu \mathrm{m})$ Bead number per $0.01 \mathrm{~mm}^{2}$ ( $\sim 50$ fibers): 2 Reduced Pressure $98.9 \mathrm{KPa}$

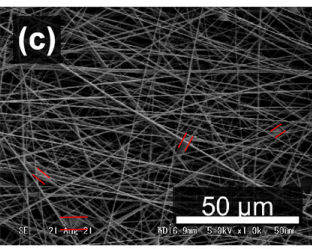

Largest bead size: $3.391(\mu \mathrm{m})$ ( 50 fibers): 4

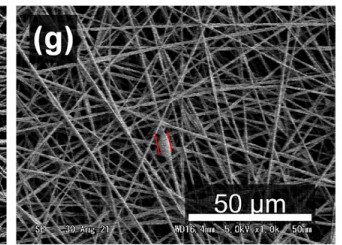

Largest bead size: $5.391(\mu \mathrm{m})$ Bead number per $0.01 \mathrm{~mm}^{2}$ ( $\sim 0$ fibers): 1 Reduced Pressure $96.6 \mathrm{KPa}$

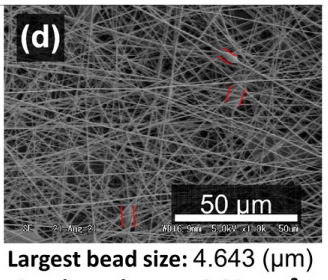

Bead number per $0.01 \mathrm{~mm}^{2}$ ( $\sim 50$ fibers): 3

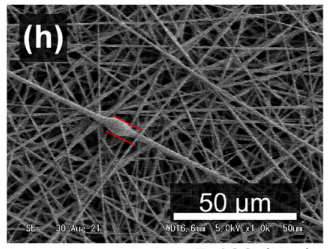

Largest bead size: $5.463(\mu \mathrm{m})$

Bead number per $0.01 \mathrm{~mm}^{2}$

( $\sim 0$ fibers): 1

Reduced Pressure

$94.4 \mathrm{KPa}$

Figure 7. SEM images of PVP8 electrospun fibers fabricated at (a) atmospheric $101.3 \mathrm{kPa}$, reduced pressure of (b) $98.9 \mathrm{kPa}$, (c) $96.6 \mathrm{kPa}$, (d) $94.4 \mathrm{kPa}$, and TTO8-PVP8 electrospun fibers fabricated at (e) atmospheric $101.3 \mathrm{kPa}$, reduced pressure of (f) $98.9 \mathrm{kPa},(\mathrm{g}) 96.6 \mathrm{kPa},(\mathbf{h}) 94.4 \mathrm{kPa}$

\subsubsection{Non-Smooth Fibers Surface by RP-ES}

10 wt.\% TTO-PVP electrospun fibers were obtained at atmospheric of Figure 8a and reduced-pressure of Figure $8 \mathrm{~b}-\mathrm{d}$ conditions. It shows that mostly smooth surface fibers were obtained during the electrospinning process conducted at atmospheric pressure. Conversely, this fiber surface morphology became unsmooth or corrugated when the process was operated at low operating pressures of RP-ES. Due to the rapid evaporation, low operating pressure seems to cause wrinkles on the fiber surface of Figure $8 b-\mathrm{d}$. When this phase separation occurred quickly, the solidified fiber skin was formed during fiber elongation before the polymer-solvent and volatile components of TTO were removed. Then, it diffused out of the fiber skin slowly, resulting in the non-smooth rougher and grooves surface morphology of the electrospun fiber [34-37].
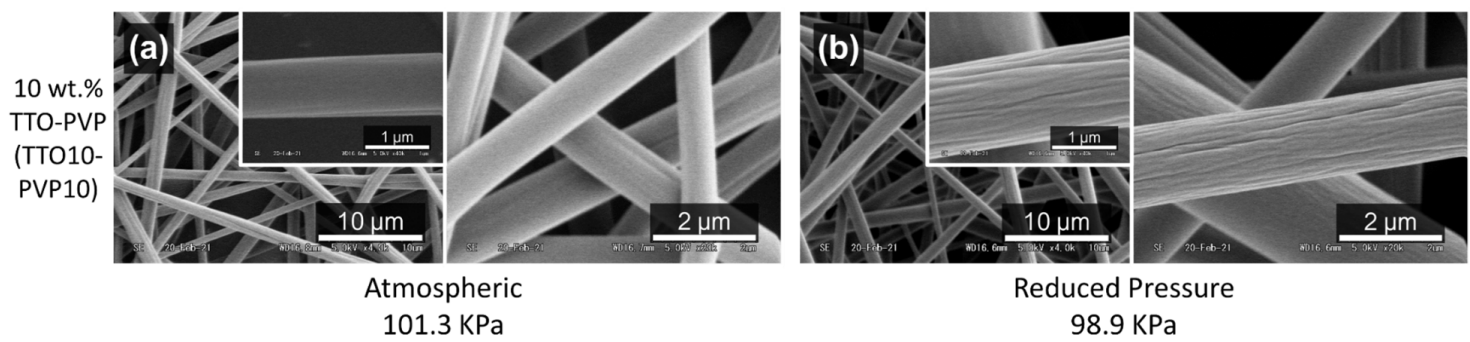

Reduced Pressure $98.9 \mathrm{KPa}$

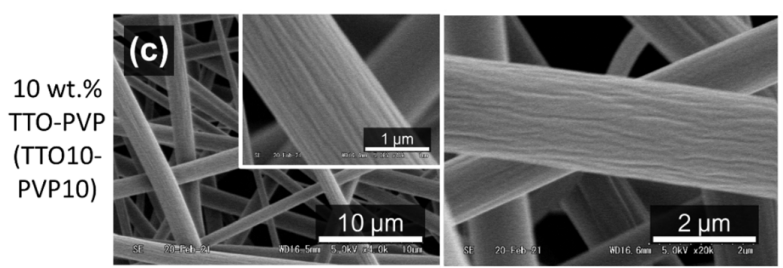

Reduced Pressure $96.6 \mathrm{KPa}$

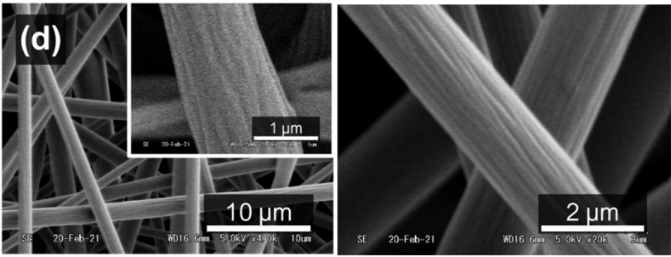

Reduced Pressure 94.4 KPa

Figure 8. SEM images of TTO10-PVP10 electrospun fibers surface fabricated at (a) atmospheric $101.3 \mathrm{kPa}$, reduced pressure of (b) $98.9 \mathrm{kPa}$, (c) $96.6 \mathrm{kPa}$, (d) $94.4 \mathrm{kPa}$. 


\subsection{Fibers Components Analysis}

\subsubsection{TTO-PVP Fibers Compounds}

The TTO essential oil extracted by steam distillation is the most widely used aromatic compound, containing various single molecular chains, molecular olefins and other chains, aromatic compounds, and alcohol groups. Here, each $2 \mathrm{mg}$ of $10 \mathrm{wt} . \%$ TTO-PVP electrospun fiber mats were dissolved in $1.5 \mathrm{~mL}$ ethanol and injected via an autosampler device into the GC-MS apparatus to observe the TTO component contents. The original TTO was dissolved in ethanol and injected into the GC-MS device as a reference. Table 1 shows the list of main TTO components that remained in the TTO-PVP electrospun fiber products fabricated under atmospheric $101.3 \mathrm{kPa}$ and reduced-pressure $94.4 \mathrm{kPa}$ conditions. The result indicates that volatile components (the components before Terpinolene of Peak No. 7 measured by GC-MS) more evaporated during micron-sized polymer solution droplets jettied at high speed, remaining a high concentration Terpinen-4-ol of low volatility.

Table 1. Main Volatile Chemotypes of TTO Determined by GC-MS.

\begin{tabular}{|c|c|c|c|c|c|c|}
\hline \multirow{2}{*}{ Peak No. } & \multirow{2}{*}{ Compound Name } & \multirow{2}{*}{ Retention Time [min] } & \multirow{2}{*}{ Boiling Point $\left[{ }^{\circ} \mathrm{C}\right]$} & \multicolumn{3}{|c|}{ Peak Area in Concentration [\%] * } \\
\hline & & & & ATM & $\mathbf{R P}$ & TTO \\
\hline 1 & $\alpha$-Pinene & 6.84 & $155-156$ & 0.72 & 0.45 & 2.28 \\
\hline 2 & $\alpha$-Terpinene & 9.64 & $173-174$ & 5.37 & 4.57 & 10.63 \\
\hline 3 & p-Cymene & 9.95 & 177 & 6.21 & 5.58 & 4.23 \\
\hline 4 & $\beta$-Phellandrene & 10.11 & $171-172$ & 1.04 & 0.87 & 1.53 \\
\hline 5 & 1,8-Cineole & 10.16 & $176-177$ & 3.92 & 3.59 & 4.29 \\
\hline 6 & $\gamma$-Terpinene & 11.29 & 183 & 15.42 & 14.04 & 21.59 \\
\hline 7 & Terpinolene & 12.52 & 184-185 & 2.90 & 2.69 & 3.60 \\
\hline 8 & Terpinen-4-ol & 16.30 & $211-213$ & 49.60 & 52.86 & 38.68 \\
\hline 9 & $\alpha$-Terpineol & 16.85 & $214-217$ & 3.62 & 4.11 & 2.82 \\
\hline 10 & Aromadendrene & 27.44 & $258-259$ & 1.84 & 1.87 & 1.23 \\
\hline 11 & Alloaromadendrene & 28.32 & $265-267$ & 0.82 & 0.85 & 0.55 \\
\hline 12 & Ledene & 29.73 & $268-270$ & 2.28 & 2.39 & 1.61 \\
\hline \multirow[t]{2}{*}{13} & $\delta$-Cadinene & 30.85 & $279-280$ & 2.66 & 2.78 & 1.81 \\
\hline & others & & & 3.61 & 3.33 & 5.15 \\
\hline
\end{tabular}

* Concentrations as relative \% of peak-area calculation from GC-MS; ATM: TTO10-PVP10 electrospun fiber fabricated at atmospheric pressure (101.3 kPa); RP: TTO10-PVP10 electrospun fiber fabricated at reduced-pressure (94.4 kPa); TTO: Tea Tree Oil.

As shown in Figure 9a,b of peak areas, the content of 1,8-Cineole (Peak 1) in TTOPVP electrospun fiber mats fabricated by RP-ES decreased by 18.18 wt.\% (Peak area decreased from 58,909,143 to 48,920,123 units), while the main functional component, Terpinen-4-ol (Peak 2), only reduced by 2.05 wt.\% (Peak area decreased from 744,520,273 to $720,972,528$ units). This TTO-PVP electrospun fiber with a lower 1,8-Cineole concentration could have a safer application prospect. It also shows that RP-ES has the intense ability to evaporate the volatiles of the mixed solution.

\subsubsection{Fibers Exposure Test}

In the electrospun fiber mats placement test, each TTO-PVP electrospun fiber (12-14 mg) was placed to ambient settings of $14-16{ }^{\circ} \mathrm{C}$ and $35-40 \%$ humidity to test the encapsulation ability of Terpinen-4-ol and 1,8-Cineole with PVP. It can be observed from Figure 10 and calculated by the standard Linear Calibration Curve of Figure 2 that at the beginning ( 0 days), Terpinen-4-ol of the TTO-PVP fiber electrospun at atmospheric pressure $(0.391(\% w / w))$ was slightly higher than that of the RP electrospun fiber $(0.383(\% w / w))$. After $10 \mathrm{~d}$ of aging, there was still a Terpinen-4-ol residual of $0.058 \mathrm{mg} / \mathrm{mg}$ in the fiber electrospun at atmospheric pressure, while the Terpinen-4-ol residual in the RP-ES fiber was $0.093 \mathrm{mg} / \mathrm{mg}$ (60.34 wt.\% higher). Because the fiber electrospun with RP-ES was thicker than that at atmospheric pressure, the Terpinen-4-ol inside the fiber was more difficult to evaporate in an exposed environment. In contrast, when using typical electrospinning or RP-ES, 1,8-Cineole 
vanished in the exposed TTO-PVP electrospun fiber on day 5 and later analysis. It indicated that 1,8-Cineole could not combine well with PVP. In addition, under room conditions, 1,8-Cineole was far more volatile than Terpinen-4-ol, which supports the hypothesis that RP-ES could evaporate and remove more 1,8-Cineole than typical electrospinning methods. It is viewed that RP-ES can produce a lower-content 1,8-Cineole of potentially toxic in TTO-PVP electrospun fibers, thus improving the application safety. In addition, GC-MS results showed that $10 \mathrm{wt} . \%$ of TTO-PVP electrospun fibers fabricated by RP-ES contained Terpinen-4-ol after placing for 10 days.
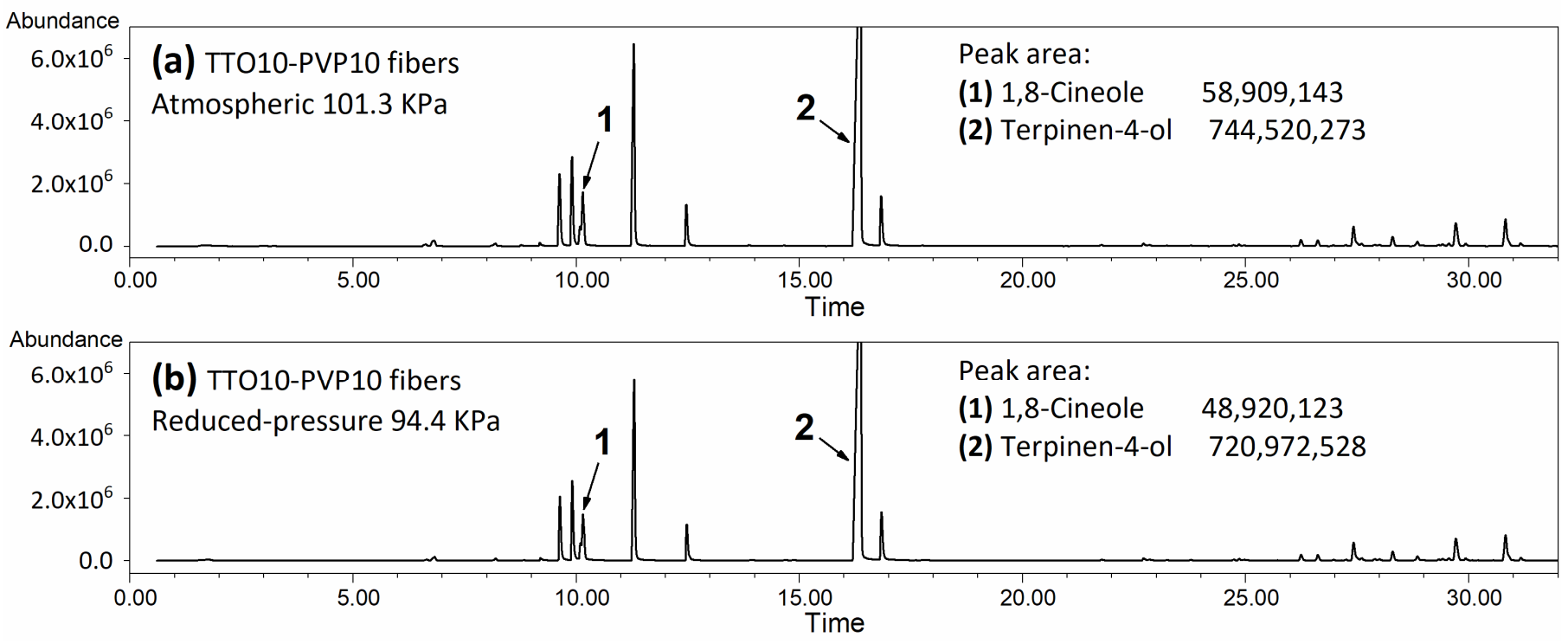

Figure 9. GC-MS traces of TTO chemotypes in $10 \mathrm{wt}$ \% TTO-PVP electrospun fibers fabricated at (a) atmospheric $101 \mathrm{kPa},(\mathbf{b})$ reduced pressure $94.4 \mathrm{kPa}$.
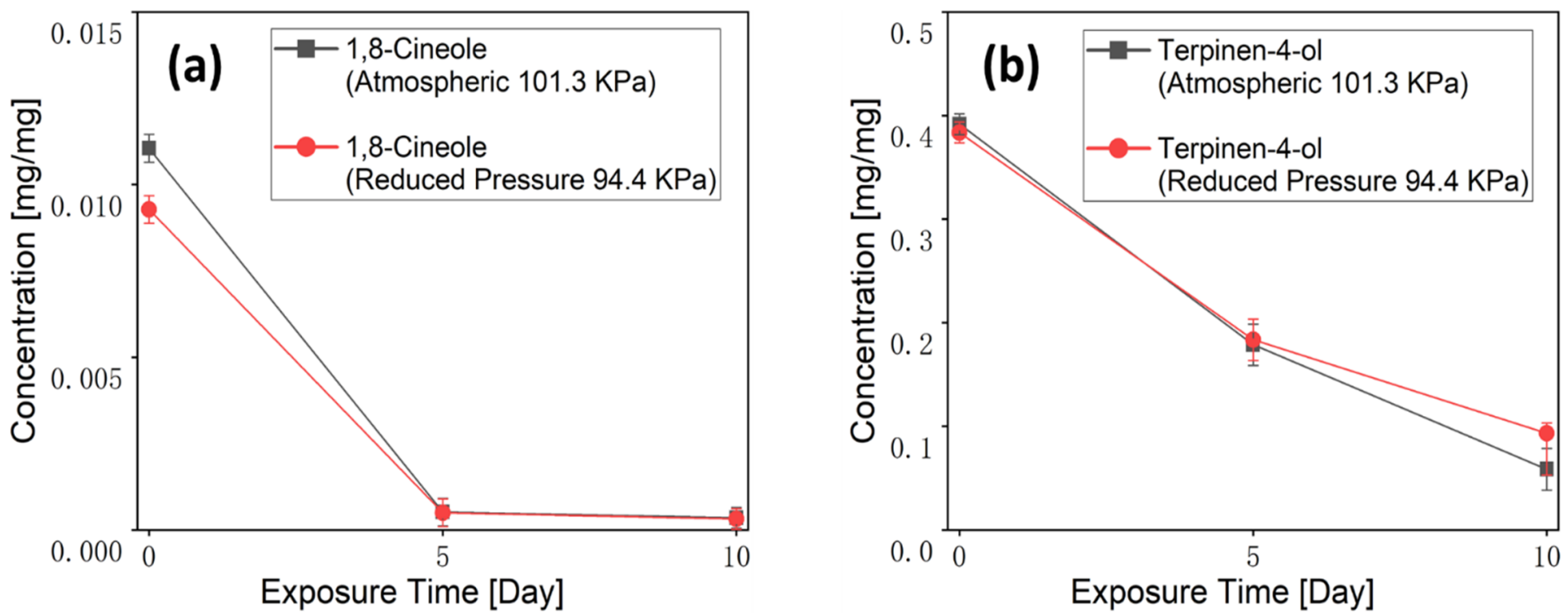

Figure 10. Concentrations of (a) 1,8-Cineole, and (b) Terpinen-4-ol in the TTO-PVP of exposed electrospun fiber. The concentrations were obtained by GC-MS analysis.

Staphylococcus aureus (S. aureus) is one of the most common bacterial infections in humans and is the causative agent of many human infections [38]. Terpinen-4-ol exhibits a strong ability of antibacterial and antibiofilm against $S$. aureus [39]. The experimental results showed that the $10 \mathrm{wt} . \%$ TTO-PVP electrospun fibers after-10-day placement (Figure 11b) had approximately 3 times the inhibition zone area on the agar compared to the pure PVP 
electrospun fibers (Figure 11a). The results showed that the $10 \mathrm{wt}$ \% TTO-PVP electrospun fibers fabricated by RP-ES had the ability to resist $S$. aureus for 10 days.

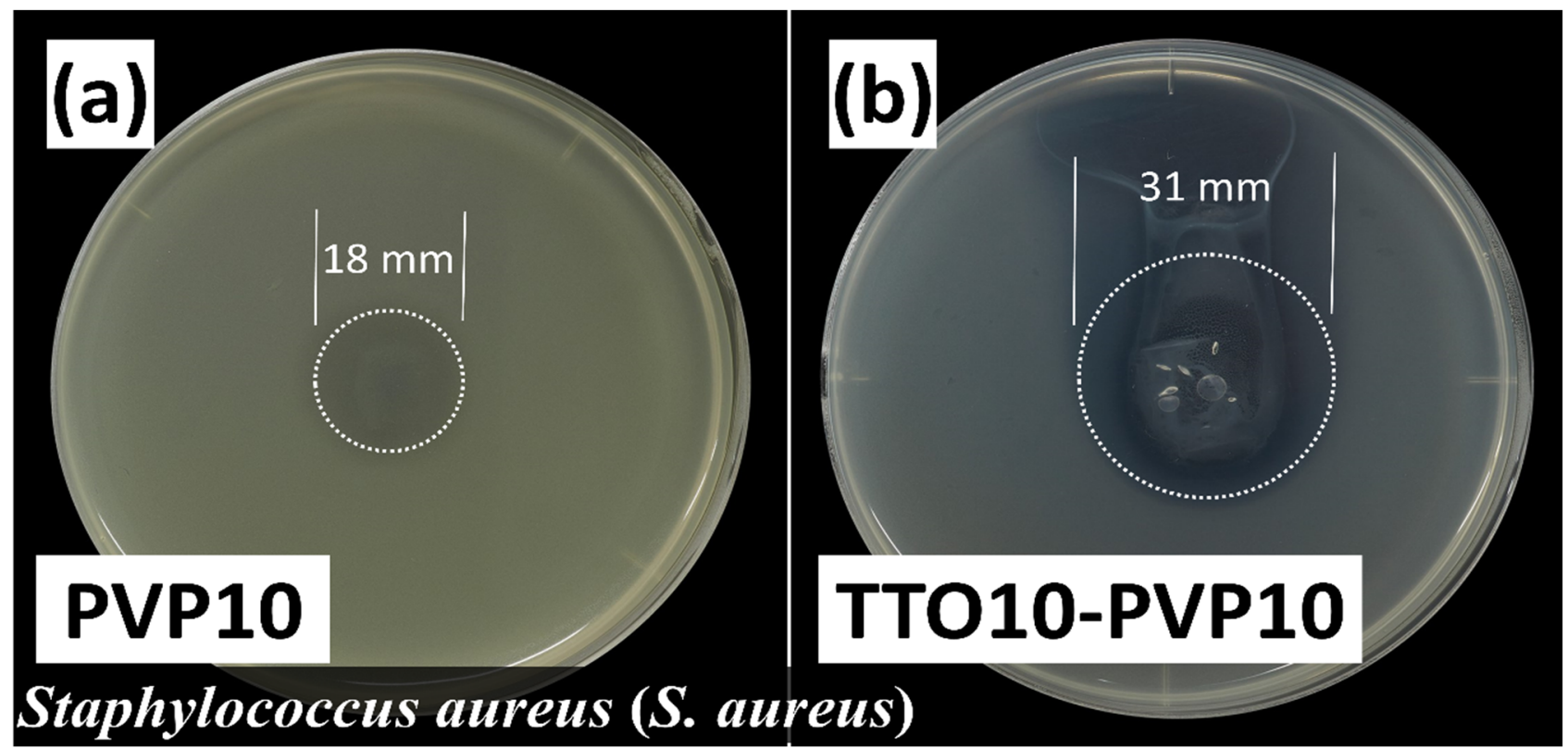

Figure 11. Inhibition zone of Staphylococcus aureus using after-10-day room condition placement of (a) 10 wt.\% PVP (b) 10 wt.\% TTO-PVP electrospun fibers fabricated by RP-ES.

\subsection{Fibers Properties Analysis \\ 3.3.1. FT-IR Analysis}

Figure 12 shows that FTIR spectroscopy could detect chemical bonds between unknown materials and compounds in these contents. Therefore, the chemical structure changes of PVP molecules with or without TTO could be observed after electrospinning. As illustrated in curve (a), for the original TTO, a strong peak at $2962 \mathrm{~cm}^{-1}$ was detected. It was ascribed to the stretching vibration peak of the $\mathrm{C}-\mathrm{H}$ bond. Absorption bands at $1126 \mathrm{~cm}^{-1}$, related to the stretching vibration of the $\mathrm{C}-\mathrm{O}$ bond of the tertiary alcohol in terpenes and terpineol, were observed [40]. This FTIR spectrum also shows a peak at $3450 \mathrm{~cm}^{-1}$, ascribed to the $\mathrm{O}-\mathrm{H}$ bond stretching vibration, and the $887 \mathrm{~cm}^{-1}, 864 \mathrm{~cm}^{-1}$, and $799 \mathrm{~cm}^{-1}$ regions are ascribed to the Terpinen-4-ol compound [41]. In curve (b) for PVP fibers, the IR peaks located at $3410 \mathrm{~cm}^{-1}, 2954 \mathrm{~cm}^{-1}, 1654 \mathrm{~cm}^{-1}, 1422 \mathrm{~cm}^{-1}, 1288 \mathrm{~cm}^{-1}$, and $841 \mathrm{~cm}^{-1}$ were assigned to the stretching vibrations of the $\mathrm{O}-\mathrm{H}, \mathrm{C}-\mathrm{H}, \mathrm{C}=\mathrm{O}, \mathrm{C}=\mathrm{C}, \mathrm{C}-\mathrm{N}$, and $=\mathrm{C}-\mathrm{H}$ groups, respectively $[42,43]$. The absorption peaks of Terpinen-4-ol were found at $887 \mathrm{~cm}^{-1}, 864 \mathrm{~cm}^{-1}$, and $799 \mathrm{~cm}^{-1}$ [41]. These results indicate that TTO has embedded PVP, and the electrospinning process at reduced pressure did not shift the properties of PVP and TTO as starting materials.

\subsubsection{Thermal Properties}

Figure 13 shows the curves of thermogravimetric-differential thermal analysis (TGDTA) under a nitrogen flow rate of $50 \mathrm{~mL} / \mathrm{min}$ with $5^{\circ} \mathrm{C} / \mathrm{min}$ increased from 40 to $500{ }^{\circ} \mathrm{C}$, where the weight shift during the analysis process was used to understand the thermal behavior of the materials and their volatile component fractions. As shown in curve (a), PVP electrospun mats show weight loss at $40-100{ }^{\circ} \mathrm{C}$, attributed to moisture evaporation. The primary weight loss of $380-460{ }^{\circ} \mathrm{C}$ could be attributed to the standard thermal decomposition of PVP. The pure TTO of the curve (e) was evaporated completely before $125{ }^{\circ} \mathrm{C}$. As shown in curves (b) and (c), electrospun fibers containing 10 wt.\% TTO have three-step weight loss, namely below $175{ }^{\circ} \mathrm{C}, 175-370{ }^{\circ} \mathrm{C}$, and over $370{ }^{\circ} \mathrm{C}$. There was no apparent difference between the two curves. When the amount of TTO in the PVP solution as the starting material increases to $15 \%$ of the curve $(\mathrm{d})$, the curve 
changes more obviously. Its results show that consistent with infrared spectroscopy analysis (see Figure 12), TTO is present in PVP electrospun fiber products. It may change the thermal stability of electrospun products through the interaction of $\mathrm{C}-\mathrm{H}$ and $\mathrm{C}=\mathrm{O}$ bond conjugation [44]. It finally indicated RP-ES could successfully fabricate the $10 \mathrm{wt} . \%$ TTOPVP of polymer solution electrospun fiber mats.

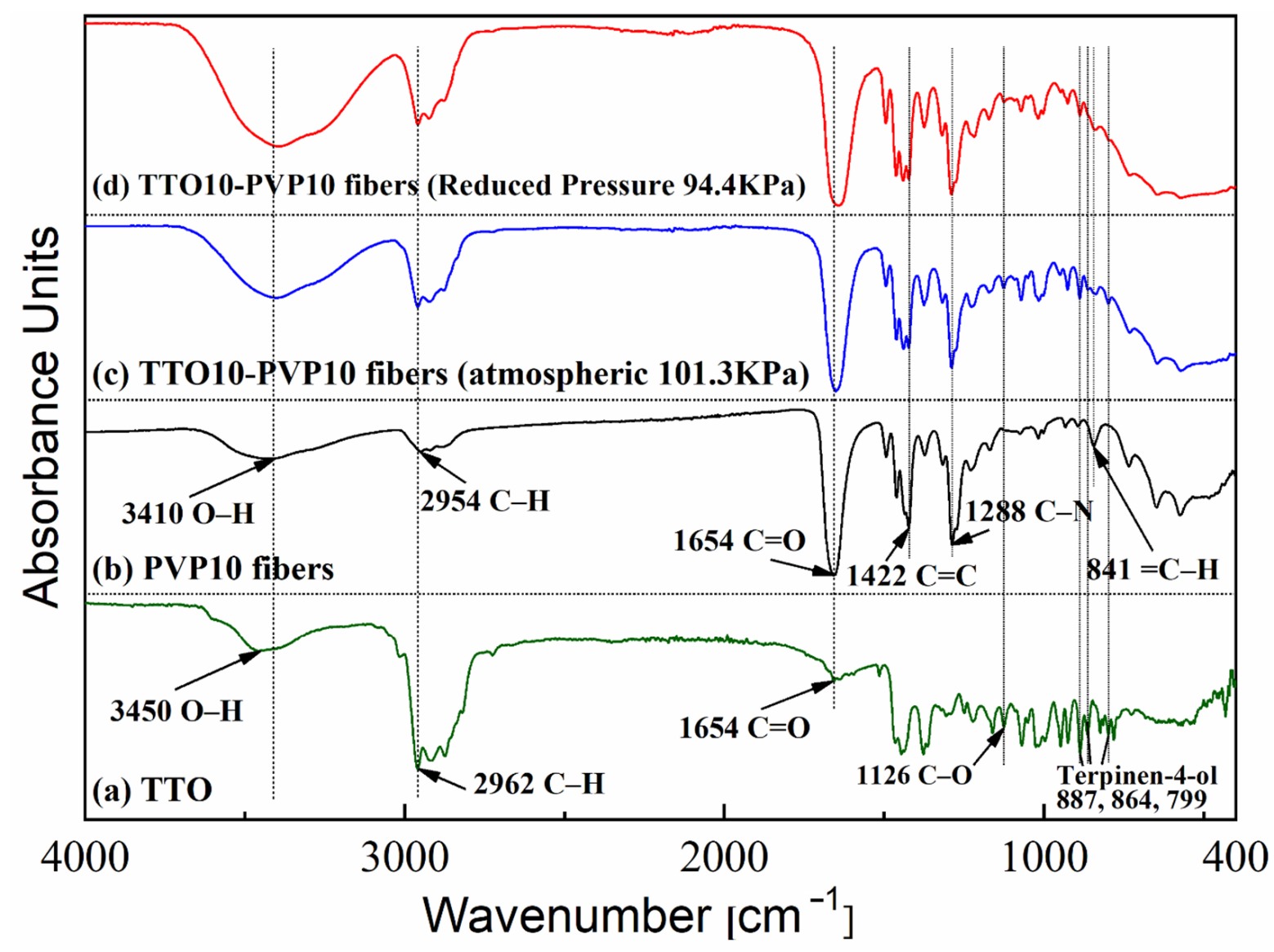

Figure 12. FTIR spectra of TTO10-PVP10 electrospun fibers fabricated at (a) reduced pressure $94.4 \mathrm{kPa}$, (b) atmospheric $101.3 \mathrm{kPa}$, (c) PVP10 electrospun fibers of atmospheric $101.3 \mathrm{kPa}$, and (d) TTO.

Figure 14 shows the curves of differential scanning calorimetry (DSC) under a Nitrogen flow rate of $50 \mathrm{~mL} / \mathrm{min}$ with $10^{\circ} \mathrm{C} / \mathrm{min}$ increased from 0 to $100{ }^{\circ} \mathrm{C}$. It can be seen that the endothermic peak of the TTO-PVP electrospun fibers (curves $(a, b)$ ) is about $15^{\circ} \mathrm{C}$ lower than that of the PVP electrospun fibers (curves (c, d)). This may be because the TTO in the TTO-PVP electrospun fibers volatilized when heated to $\sim 60^{\circ} \mathrm{C}$ resulting in the need for endothermic heat of the fibers mat. In addition, probably because more volatilized components such as 1,8-Cineole were already evaporated during the preparation of fibers by RP-ES, the endothermic peak of TTO-PVP by RP-ES (curve (a)) was $1^{\circ} \mathrm{C}$ higher than by typical electrospinning (curve (b)). Similarly, for the pure PVP electrospun fibers produced by RP-ES (curve (c)), the evaporation of the solvent could be more intense, resulting in drier fiber mats, causing the endothermic peak to shift $1.5^{\circ} \mathrm{C}$ higher than by typical electrospinning. It further supported the enhanced evaporation of RP-ES for polymer solvents and volatile components. 


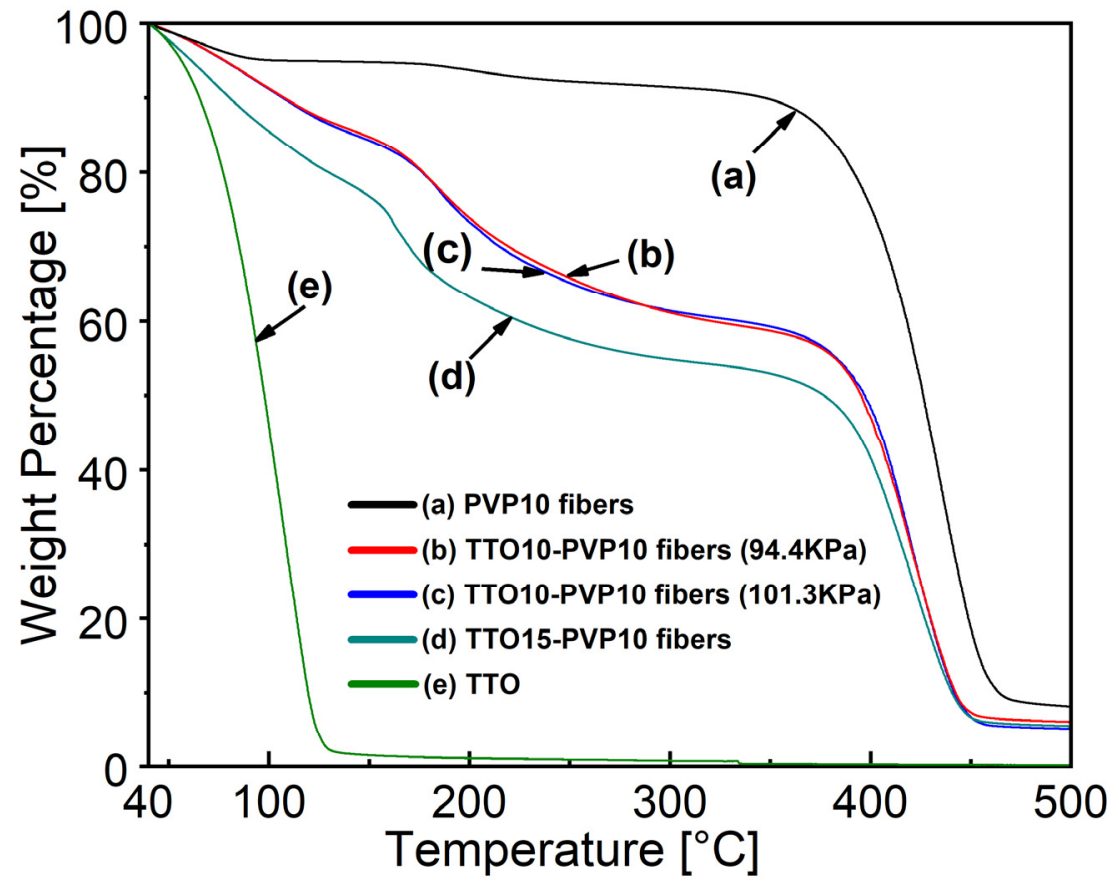

Figure 13. TGA thermogram of (a) PVP10 electrospun fibers of atmospheric $101.3 \mathrm{kPa}$, TTO10PVP10 electrospun fibers fabricated at (b) reduced pressure $94.4 \mathrm{kPa}$, (c) atmospheric $101.3 \mathrm{kPa}$, (d) TTO15-PVP10 electrospun fiber of atmospheric $101.3 \mathrm{kPa}$, and (e) TTO.

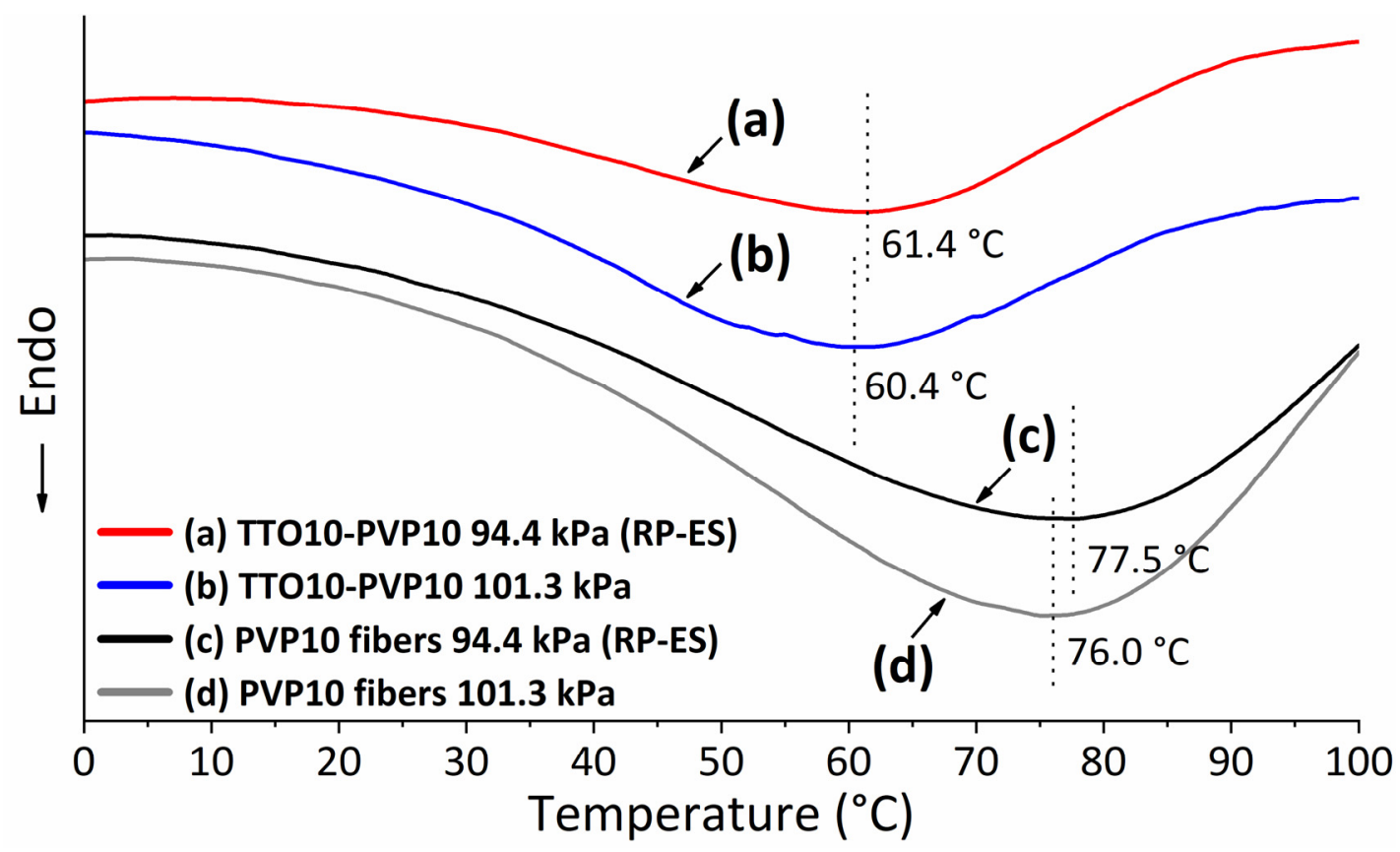

Figure 14. DSC analysis of TTO10-PVP10 electrospun fibers fabricated at (a) reduced pressure $94.4 \mathrm{kPa}$, (b) atmospheric $101.3 \mathrm{kPa}$, and PVP10 electrospun fibers fabricated at (c) reduced pressure $94.4 \mathrm{kPa}$, (d) atmospheric $101.3 \mathrm{kPa}$.

\subsection{Mechanism of Enhanced Evaporation by RP-ES}

The above results indicate that the evaporation of polymer-solvent and TTO volatile components in RP-ES was enhanced. This paper attempts to illustrate the mechanism of enhanced evaporation of polymer-solvent ethanol. As shown in Figure $15 \mathrm{a}, \mathrm{b}$ the average angle of the Taylor cone increased from $72^{\circ}$ to $76^{\circ}$, which may be attributed to the stronger evaporation of ethanol in the Taylor cone area that increased the concentration PVP in the 
polymer solution at the Taylor cone region. As the viscosity of polymer solution increases, resulting in stronger cohesion between the PVP chains and making it impossible to stretch the molecules further that increased fiber diameter [45-47].
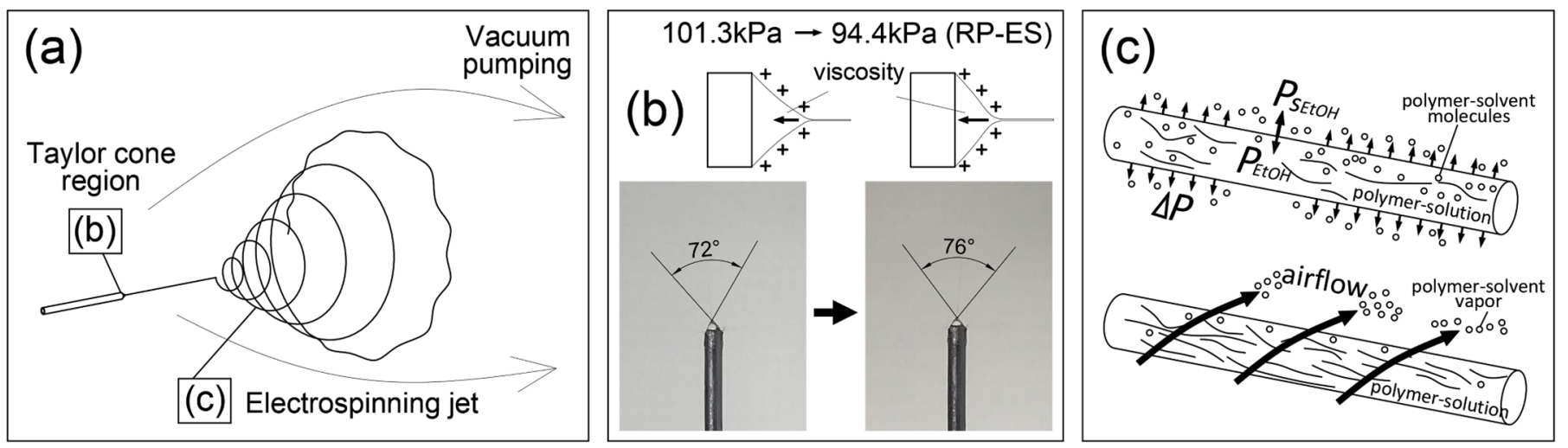

Figure 15. (a) Reduce pressure electrospinning process; (b) evaporation of Taylor cone area; (c) evaporation of electrospinning jet.

As shown in Figure 15a,c during the electrospinning jet, as the total pressure of the electrospinning ambient environment decreases by continuous vacuum pumping, the actual vapor pressure of the polymer-solution liquid surface is simultaneously reduced by the partial pressures of Dalton's law. According to Dalton's law, the total pressure $P_{\text {tot }}$ is detailed as,

$$
\begin{gathered}
P_{\text {tot }}=P_{E t O H}+P_{\text {air }} \\
P_{\text {tot }}=n P_{E t O H}
\end{gathered}
$$

It leads to an enlarged polymer-solvent pressure difference $\Delta P_{E t O H}$ between the saturated vapor pressure $P_{S_{E t O H}}$ and actual vapor pressure $P_{E t O H}$ at a fixed temperature, which results in intense vapor diffusion. The pressure difference $\Delta P_{E t O H}$ is detailed as,

$$
\Delta P_{E t O H}=P_{S_{E t O H}}-P_{E t O H}
$$

with the greater $\Delta P_{E t O H}$, the evaporation shall be faster. Simultaneously, from the relative humidity $(R H)$ perspective, the partial water vapor pressure $P$ decreases because water molecules are continuously vacuum pumping, causing an increased water pressure difference $\Delta P$ as,

$$
\Delta P=P S-P=P s(1-R H)
$$

Here, $P s$ is the saturated water vapor pressure. When the water vapor molecules were pumped away, the dropped in $P$ led to the dropped in $R H$. Several recent studies have identified ambient $R H$ is critical in controlling aqueous polymer-solvent evaporation during electrospinning [48-50]. Pelipenko et al. [51] and Vrieze et al. [52], found that a decreasing $R H$ led to an increased diameter of PVP electrospun fibers. Here, since PVP can be dissolved in water, the moisture absorption around PVP was less under a low $R H$. Therefore, as the PVP solidified, the electrospun fiber cannot be elongated anymore, resulting in thicker fibers [53], which agrees with our observations in this study.

In addition, Figure 15c shows that the fresh airflow by continuous vacuum pumping could blow away the polymer-solvent vapor and maintain a significant vapor concentration difference that tends to benefit a long-time working electrospinning system.

\section{Conclusions}

Compared with typical electrospinning methods, RP-ES can enhance the evaporation of the polymer-solvent, thereby increasing the viscosity of the polymer solution in the Taylor cone region and the process of jetting. This results in (1) thicker fibers, (2) fewer and 
size reduced bead of fibers, and (3) non-smooth grooves fiber surface morphology. FT-IR and TG results showed that RP-ES did not change functional groups and thermal properties of TTO-PVP electrospun fibers. In addition, with an $18.18 \mathrm{wt} . \%$ decreased concentration of 1,8-Cineole, making this product safer for application. Based on the results and owing to the enhanced evaporation capacity of RP-ES, it seems that, by reduced pressure and continuous vacuum pumping to remove water and solvent vapor, RP-ES tends to keep working longer than current electrospinning methods.

Author Contributions: Conceptualization, L.Z. and W.; Data curation, L.Z., S.M. and W.; Investigation, L.Z., S.M. and W.; Methodology, L.Z. and W.; Project administration, H.K. and M.G.; Resources, H.K. and M.G.; Supervision, M.G.; Visualization, L.Z., W. and H.K.; Writing-review \& editing, H.K. All authors have read and agreed to the published version of the manuscript.

Funding: This work was supported by JST SICORP (Grant Number JPMJSC18H1), Japan.

Institutional Review Board Statement: Not applicable.

Informed Consent Statement: Not applicable.

Data Availability Statement: Not applicable.

Conflicts of Interest: The authors declare no conflict of interest.

\section{References}

1. Pazyar, N.; Yaghoobi, R.; Bagherani, N.; Kazerouni, A. A review of applications of tea tree oil in dermatology. Int. J. Dermatol. 2013, 52, 784-790. [CrossRef]

2. Salvatori, C.; Barchi, L.; Guzzo, F.; Gargari, M. A comparative study of antibacterial and anti-inflammatory effects of mouthrinse containing tea tree oil. Oral Implantol. 2017, 10, 59. [CrossRef] [PubMed]

3. Ge, Y.; Ge, M. Sustained broad-spectrum antimicrobial and haemostatic chitosan-based film with immerged tea tree oil droplets. Fibers Polym. 2015, 16, 308-318. [CrossRef]

4. Da Silva, N.P.; do Carmo Rapozo Lavinas Pereira, E.; Duarte, L.M.; de Oliveira Freitas, J.C.; de Almeida, C.G.; da Silva, T.P.; Melo, R.C.N.; Morais Apolônio, A.C.; de Oliveira, M.A.L.; de Mello Brandão, H.; et al. Improved anti-Cutibacterium acnes activity of tea tree oil-loaded chitosan-poly( $\varepsilon$-caprolactone) core-shell nanocapsules. Colloids Surf. B Biointerfaces 2020, 196, 111371. [CrossRef] [PubMed]

5. El-Wakil, A.E.-A.A.; Moustafa, H.; Youssef, A.M. Antimicrobial low-density polyethylene/low-density polyethylene-grafted acrylic acid biocomposites based on rice bran with tea tree oil for food packaging applications. J. Thermoplast. Compos. Mater. 2020, 5, 1-19. [CrossRef]

6. Cordeiro, L.; Figueiredo, P.; Souza, H.; Sousa, A.; Andrade-Júnior, F.; Medeiros, D.; Nóbrega, J.; Silva, D.; Martins, E.; BarbosaFilho, J.; et al. Terpinen-4-ol as an Antibacterial and Antibiofilm Agent against Staphylococcus aureus. Int. J. Mol. Sci. 2020, $21,4531$. [CrossRef]

7. Hammer, K.A.; Carson, C.F.; Riley, T.V. Effects of Melaleuca alternifolia (Tea Tree) Essential Oil and the Major Monoterpene Component Terpinen-4-ol on the Development of Single- and Multistep Antibiotic Resistance and Antimicrobial Susceptibility. Antimicrob. Agents Chemother. 2012, 56, 909. [CrossRef]

8. Loughlin, R.; Gilmore, B.F.; McCarron, P.A.; Tunney, M.M. Comparison of the cidal activity of tea tree oil and terpinen-4-ol against clinical bacterial skin isolates and human fibroblast cells. Lett. Appl. Microbiol. 2008, 46, 428-433. [CrossRef]

9. Nogueira, M.N.M.; Aquino, S.G.; Rossa Junior, C.; Spolidorio, D.M.P. Terpinen-4-ol and alpha-terpineol (tea tree oil components) inhibit the production of IL-1 $\beta$, IL-6 and IL-10 on human macrophages. Inflamm. Res. 2014, 63, 769-778. [CrossRef]

10. Tighe, S.; Gao, Y.Y.; Tseng, S.C.G. Terpinen-4-ol is the Most Active Ingredient of Tea Tree Oil to Kill Demodex Mites. Transl. Vis. Sci. Technol. 2013, 2, 2. [CrossRef]

11. Di Campli, E.; Di Bartolomeo, S.; Delli Pizzi, P.; Di Giulio, M.; Grande, R.; Nostro, A.; Cellini, L. Activity of tea tree oil and nerolidol alone or in combination against Pediculus capitis (head lice) and its eggs. Parasitol. Res. 2012, 111, 1985-1992. [CrossRef] [PubMed]

12. Lee, C.-J.; Chen, L.-W.; Chen, L.-G.; Chang, T.-L.; Huang, C.-W.; Huang, M.-C.; Wang, C.-C. Correlations of the components of tea tree oil with its antibacterial effects and skin irritation. J. Food Drug Anal. 2013, 21, 169-176. [CrossRef]

13. Xu, J.; Hu, Z.-Q.; Wang, C.; Yin, Z.-Q.; Wei, Q.; Zhou, L.-J.; Li, L.; Du, Y.-H.; Jia, R.-Y.; Li, M.; et al. Acute and subacute toxicity study of 1,8-cineole in mice. Int. J. Clin. Exp. Pathol. 2014, 7, 1495-1501.

14. Caldas, G.F.R.; Limeira, M.M.F.; Araújo, A.V.; Albuquerque, G.S.; da Costa Silva-Neto, J.; da Silva, T.G.; Costa-Silva, J.H.; de Menezes, I.R.A.; da Costa, J.G.M.; Wanderley, A.G. Repeated-doses and reproductive toxicity studies of the monoterpene 1,8-cineole (eucalyptol) in Wistar rats. Food Chem. Toxicol. 2016, 97, 297-306. [CrossRef] [PubMed]

15. Li, F.; Peng, C.; Yuan, K.; Xu, Q.; Song, H. Deterpenation of tea tree oil by liquid-liquid extraction with hexalkylguanidinium ionic liquid. J. Mol. Liq. 2021, 339, 117048. [CrossRef] 
16. Riddick, J.; Bunger, W.; Sakano, T. Techniques of Chemistry, Organic Solvents; John Wiley and Sons: New York, NY, USA, 1985; Volume 2 .

17. Gimeno, B.; Martinez, S.; Urieta, J.S.; Perez, P. Vapor Pressures and Activity Coefficients of (1-Propanol+ 1, 8-Cineole) at 10 Temperatures between $278.15 \mathrm{~K}$ and 323.15 K. J. Chem. Eng. Data 2012, 57, 3026-3031. [CrossRef]

18. Hoskovec, M.; Grygarová, D.; Cvačka, J.; Streinz, L.; Zima, J.; Verevkin, S.P.; Koutek, B. Determining the vapour pressures of plant volatiles from gas chromatographic retention data. J. Chromatogr. A 2005, 1083, 161-172. [CrossRef]

19. Tranchida, P.Q.; Shellie, R.A.; Purcaro, G.; Conte, L.S.; Dugo, P.; Dugo, G.; Mondello, L. Analysis of Fresh and Aged Tea Tree Essential Oils By Using GC $\times$ GC-qMS. J. Chromatogr. Sci. 2010, 48, 262-266. [CrossRef]

20. Homer, L.E.; Leach, D.N.; Lea, D.; Lee, L.S.; Henry, R.J.; Baverstock, P.R. Natural variation in the essential oil content of Melaleuca alternifolia Cheel (Myrtaceae). Biochem. Syst. Ecol. 2000, 28, 367-382. [CrossRef]

21. Huang, Y.; Dan, N.; Dan, W. Promising Biomedical Material Based on Collagen Composite Electrospun Nanofibers: A Review. Mater. Rev. 2019, 33, 3322-3327.

22. Cao, G.; Li, Y.; Qi, Y.; Qiao, Y.; He, J.; Zhang, H.; Cui, W.; Zhou, M. NIR-responsible and optically monitored nanoparticles release from electrospinning fibrous matrices. Mater. Today Adv. 2020, 6, 100044. [CrossRef]

23. Niamlang, P.; Supaphol, P.; Morlock, G.E. Performance of Electropun Polyacrylonitrile Nanofibrous Phases, Shown for the Separation of Water-Soluble Food Dyes via UTLC-Vis-ESI-MS. Nanomaterials 2017, 7, 218. [CrossRef] [PubMed]

24. Zhang, W.; Huang, C.; Kusmartseva, O.; Thomas, N.L.; Mele, E. Electrospinning of polylactic acid fibres containing tea tree and manuka oil. React. Funct. Polym. 2017, 117, 106-111. [CrossRef]

25. Ge, Y.; Tang, J.; Fu, H.; Fu, Y.; Wu, Y. Characteristics, Controlled-release and Antimicrobial Properties of Tea Tree Oil Liposomesincorporated Chitosan-based Electrospun Nanofiber Mats. Fibers Polym. 2019, 20, 698-708. [CrossRef]

26. Cui, H.; Bai, M.; Lin, L. Plasma-treated poly(ethylene oxide) nanofibers containing tea tree oil/beta-cyclodextrin inclusion complex for antibacterial packaging. Carbohydr. Polym. 2018, 179, 360-369. [CrossRef] [PubMed]

27. Lee, J.Y.; Lee, J.; Ko, S.W.; Son, B.C.; Lee, J.H.; Kim, C.S.; Park, C.H. Fabrication of Antibacterial Nanofibrous Membrane Infused with Essential Oil Extracted from Tea Tree for Packaging Applications. Polymers 2020, 12, 125. [CrossRef]

28. Rasekh, M.; Karavasili, C.; Soong, Y.L.; Bouropoulos, N.; Morris, M.; Armitage, D.; Li, X.; Fatouros, D.G.; Ahmad, Z. Electrospun PVP-indomethacin constituents for transdermal dressings and drug delivery devices. Int. J. Pharm. 2014, 473, 95-104. [CrossRef]

29. Mei, L.; Han, R.; Gao, Y.; Fu, Y.; Liu, Y. Effect of electric field intensity on the morphology of magnetic-field-assisted electrospinning PVP nanofibers. J. Wuhan Univ. Technol. Mater. Sci. Ed. 2013, 28, 1107-1111. [CrossRef]

30. Khorrami, S.; Zarrabi, A.; Khaleghi, M.; Danaei, M.; Mozafari, M.R. Selective cytotoxicity of green synthesized silver nanoparticles against the MCF-7 tumor cell line and their enhanced antioxidant and antimicrobial properties. Int. J. Nanomed. 2018, 13, 8013-8024. [CrossRef]

31. Kesici Güler, H.; Cengiz Çallığlu, F.; Sesli Çetin, E. Antibacterial PVP/cinnamon essential oil nanofibers by emulsion electrospinning. J. Text. Inst. 2019, 110, 302-310. [CrossRef]

32. Chuangchote, S.; Sagawa, T.; Yoshikawa, S. Electrospinning of poly(vinyl pyrrolidone): Effects of solvents on electrospinnability for the fabrication of poly(p-phenylene vinylene) and TiO2 nanofibers. J. Appl. Polym. Sci. 2009, 114, 2777-2791. [CrossRef]

33. Higashi, S.; Hirai, T.; Matsubara, M.; Yoshida, H.; Beniya, A. Dynamic viscosity recovery of electrospinning solution for stabilizing elongated ultrafine polymer nanofiber by TEMPO-CNF. Sci. Rep. 2020, 10, 13427. [CrossRef] [PubMed]

34. Munir, M.M.; Suryamas, A.B.; Iskandar, F.; Okuyama, K. Scaling law on particle-to-fiber formation during electrospinning. Polymer 2009, 50, 4935-4943. [CrossRef]

35. Ma, G.; Yang, D.; Zhou, Y.; Jin, Y.; Nie, J. Preparation and characterization of chitosan/poly(vinyl alcohol)/poly(vinyl pyrrolidone) electrospun fibers. Front. Mater. Sci. China 2007, 1, 432-436. [CrossRef]

36. Huang, C.; Tang, Y.; Liu, X.; Sutti, A.; Ke, Q.; Mo, X.; Wang, X.; Morsi, Y.; Lin, T. Electrospinning of nanofibres with parallel line surface texture for improvement of nerve cell growth. Soft Matter 2011, 7, 10812-10817. [CrossRef]

37. Zhao, L.; Liu, P.; He, J.-H. Sudden solvent evaporation in bubble electrospinning for fabrication of unsmooth nanofibers. Therm. Sci. 2017, 21, 1827-1832. [CrossRef]

38. Taylor, T.; Unakal, C. Staphylococcus Aureus; StatPearls Publishing: Treasure Island, FL, USA, 2021.

39. Carson, C.F.; Mee, B.J.; Riley, T.V. Mechanism of action of Melaleuca alternifolia (tea tree) oil on Staphylococcus aureus determined by time-kill, lysis, leakage, and salt tolerance assays and electron microscopy. Antimicrob. Agents Chemother. 2002, 46, 1914-1920. [CrossRef]

40. Lin, G.; Chen, H.; Zhou, H.; Zhou, X.; Xu, H. Preparation of Tea Tree Oil/Poly(styrene-butyl methacrylate) Microspheres with Sustained Release and Anti-Bacterial Properties. Materials 2018, 11, 710. [CrossRef]

41. Rytwo, G.; Zakai, R.; Wicklein, B. The Use of ATR-FTIR Spectroscopy for Quantification of Adsorbed Compounds. J. Spectrosc. 2015, 2015, 727595. [CrossRef]

42. Machmudah, S.; Winardi, S.; Wahyudiono; Kanda, H.; Goto, M. Formation of Fine Particles from Curcumin/PVP by the Supercritical Antisolvent Process with a Coaxial Nozzle. ACS Omega 2020, 5, 6705-6714. [CrossRef]

43. Jia, Y.; Huang, G.; Dong, F.; Liu, Q.; Nie, W. Preparation and characterization of electrospun poly(E-caprolactone)/poly(vinyl pyrrolidone) nanofiber composites containing silver particles. Polym. Compos. 2016, 37, 2847-2854. [CrossRef]

44. Schneider, C.A.; Rasband, W.S.; Eliceiri, K.W. NIH Image to ImageJ: 25 years of image analysis. Nat. Methods 2012, 9, 671-675. [CrossRef] [PubMed] 
45. Swei, J.; Talbot, J.B. Viscosity correlation for aqueous polyvinylpyrrolidone (PVP) solutions. J. Appl. Polym. Sci. 2003, 90, 1153-1155. [CrossRef]

46. Chen, X.; Zhang, Y.; He, X.; Li, H.; Wei, B.; Yang, W. Electrospinning on a plucked string. J. Mater. Sci. 2019, 54, 901-910. [CrossRef]

47. Yang, Q.; Li, Z.; Hong, Y.; Zhao, Y.; Qiu, S.; Wang, C.; Wei, Y. Influence of solvents on the formation of ultrathin uniform poly(vinyl pyrrolidone) nanofibers with electrospinning. J. Polym. Sci. Part B Polym. Phys. 2004, 42, 3721-3726. [CrossRef]

48. Cai, Y.; Gevelber, M. Analysis of bending region physics in determining electrospun fiber diameter: Effect of relative humidity on evaporation and force balance. J. Mater. Sci. 2017, 52, 2605-2627. [CrossRef]

49. Huang, L.; Bui, N.-N.; Manickam, S.S.; McCutcheon, J.R. Controlling electrospun nanofiber morphology and mechanical properties using humidity. J. Polym. Sci. Part B Polym. Phys. 2011, 49, 1734-1744. [CrossRef]

50. Ying, Y.; Zhidong, J.; Qiang, L.; Zhicheng, G. Experimental investigation of the governing parameters in the electrospinning of polyethylene oxide solution. IEEE Trans. Dielectr. Electr. Insul. 2006, 13, 580-585. [CrossRef]

51. Pelipenko, J.; Kristl, J.; Janković, B.; Baumgartner, S.; Kocbek, P. The impact of relative humidity during electrospinning on the morphology and mechanical properties of nanofibers. Int. J. Pharm. 2013, 456, 125-134. [CrossRef]

52. De Vrieze, S.; Van Camp, T.; Nelvig, A.; Hagström, B.; Westbroek, P.; De Clerck, K. The effect of temperature and humidity on electrospinning. J. Mater. Sci. 2009, 44, 1357-1362. [CrossRef]

53. Mailley, D.; Hébraud, A.; Schlatter, G. A Review on the Impact of Humidity during Electrospinning: From the Nanofiber Structure Engineering to the Applications. Macromol. Mater. Eng. 2021, 306, 2100115. [CrossRef] 